\title{
A Patch Test-Confirmed Mefenamic Acid-Induced Fixed Drug Eruption in a Tunisian Woman
}

\author{
Mariem Mohamed ${ }^{1 *}$, Nadia Nabli ${ }^{1}$, Saber Zerriaa ${ }^{1}$, Yosra Soua ${ }^{1}$, Leila Njim$^{2}$, Nadia Ben Fredj ${ }^{3}$, \\ Hichem Belhadjali ${ }^{1}$, Karim Aouem ${ }^{3}$ and Jameleddine Zili ${ }^{1}$ \\ ${ }^{1}$ Department of Dermatology, Monastir University Hospital, Faculty of Medicine of Monastir, Monastir, Tunisia \\ ${ }^{2}$ Department of Pathology, Monastir University Hospital, Faculty of Medicine of Monastir, Monastir, Tunisia \\ ${ }^{3}$ Department of Pharmacology, Faculty of Medicine of Monastir, Monastir, Tunisia
}

Received: November 03, 2016; Accepted: November 23, 2016; Published: November 24, 2016

*Corresponding author: M Mohamed, Department of Dermatology, Monastir University Hospital, Faculty of Medicine of Monastir, Monastir, Tunisia, E-mail: mariemmohamed79@yahoo.fr

\section{Introduction}

Mefenamic acid is a nonsteroidal anti-inflammatory inhibitor of cyclooxygenase 1 and 2. Only a few cases of fixed drug eruptions induced by this drug have been reported [1-7]. We report on a new case of multifocal FDE caused by mefenamic acid and confirmed by patch testing.

\section{Case Report}

A 47-year-old woman with a 2-year history of renal failure presented at our department for pruritic, erythematous and hyper pigmented lesions, $1-3 \mathrm{~cm}$ in diameter, on the face, trunk and extremities. Some lesions were blistering and erosive (figure 1). The patient reported that the eruption began 1 year earlier. Since, the lesions relapsed frequently, tended to proliferate and worsen, and resolved spontaneously after few weeks with residual hyper pigmentation. The patient noticed also that the lesions became inflamed within a few hours of administration of mefenamic acid for dysmenorrhoea.

Routine laboratory tests revealed markers of inflammation (CRP and ESR concentrations, and leukocyte counts) significantly higher than normal values, and elevated creatinine concentration and anemia related to her renal failure. Biopsies of skin lesions showed vacuolar interface dermatitis with necrotic keratinocytes and a predominantly lymphohistiocytic inflammatory infiltrate with neutrophils and eosinophils (Figure 2).

Based on the clinical and histopathologic findings, we diagnosed multifocal FDE due to mefenamic acid. Patch tests performed with mefenamic acid, $30 \%$ in petrolatum, applied on healthy and lesional skin were positive on lesional skin (Figure 3 ). The patient was advised to stop taking mefenamic acid and no further episodes of skin inflammation were reported after a mean follow-up of 1 year.

\section{Discussion}

FDE was first described by Bourns [8] in 1889. It is defined by the appearance of skin and/or mucosal hyper pigmented lesions that may persist for months or years, and relapse at the same location after readministration of the responsible drug [9]. It represents a IVc type drug- induced reaction of the skin and mucous membranes [10].

FDE can affect any age group from childhood to older age, but most commonly affected individuals are aged 20-40 years [3]. Association with HLA-B22 has been reported [11]. Cutaneous and mucosal lesions appear minutes to hours after administration of the sensitizing medication [12]. They are observed mostfrequently

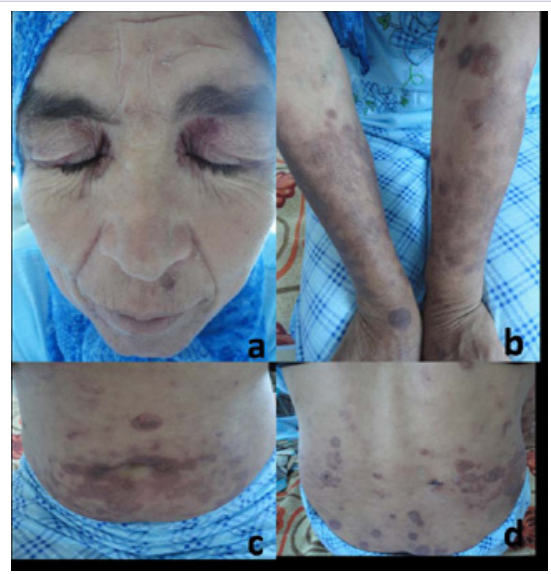

Figure 1: Multiple pruritic, erythematous and hyper pigmented patches, $1-3 \mathrm{~cm}$ in diameter with some blisters and erosions on the face (a), forearm (b), abdomen (c) and back (d)

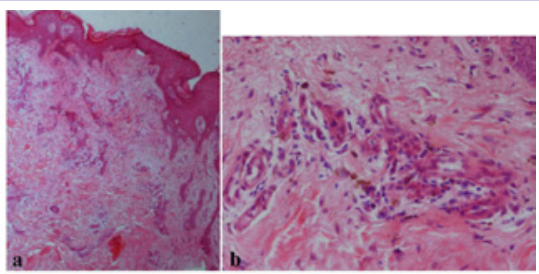

Figure 2: Vacuolar interface dermatitis with necrotic keratinocyte and a predominantly lymphohistiocytic inflammatory infiltrate with neutrophils and eosinophils; (a) H and E X 40 and (b) Hand E X 200 


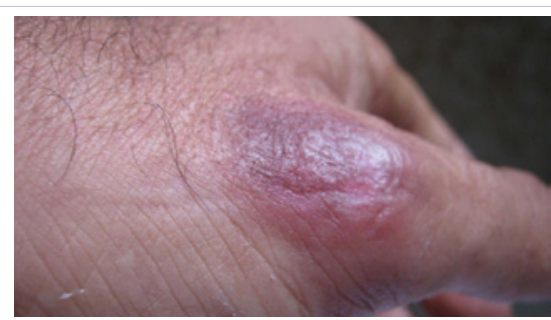

Figure 3: positive reaction of patch test performed with Mefenamic acid $30 \%$ in petrolatum

after oral than intravenous, intramuscular administrations or topical application [3]. Occurrence after sexual contact with a partner who had taken the eliciting drug has been reported [13]. Clinically, FDE is characterized by the sudden appearance of one or several round, sharply defined erythematous maculae on the skin or mucosal membranes after drug administration. The lesions have a size of several millimeters up to $10 \mathrm{~cm}$. They can rapidly progress to edematous plaques and can occasionally vesiculate or blister. On the mucosal membranes, erosions are often seen. Sites of predilection are the palms and soles, the medial aspects of the limbs, abdomen, but also lips, tongue, oral mucosa and in men the glans penis.

The lesions are often asymptomatic, but burning and pruritus at the involved sites are reported $[12,14]$.

Rarely, systemic signs and symptoms such as malaise, anorexia, fever, diarrhea, nausea and abdominal complaints occur.

A wide range of drugs can trigger FDE, but the most common ones are antibiotics (particularly co-trimoxazole), anticonvulsants, and analgesics.

The most common offending agents include antimicrobials mainly co-trimoxazole, nonsteroidal anti-inflammatory drugs, and antiepileptic [3].

Mefenamic acid, an anthranilic acid derivative, is a nonsteroidal anti-inflammatory anti-rheumatic drug. It has analgesic, antiphlogistic and antipyretic effects via inhibition of prostaglandin synthesis. It is used to treat acute and chronic pain such as in rheumatic diseases, primary dysmenorrhea, after trauma and surgery as well as muscular and spinal pain.

Mefenamic acid is frequently taken without any medical advice. The association of the drug with a possible FDE may be difficult because the use of mefenamic acid is occasional and usually forgotten by the patients. Only few cases of PFE induced by mefenamic acid have been reported $[1,2,15]$. In the diagnostic work-up of fixed drug eruption, provocation tests represent the gold standard [3]. Patch testing with the presumed drug will give positive results mainly when it is applied to the affected skin. In our case, patch tests with mefenamic acid, $30 \%$ in petrolatum, applied to lesional skin were positive. However, the sensitivity of patch-tests with drugs in FDE does not exceed 40-50\%, and negative responses in patch-tests do not rule-out diagnosis of FDE [16].

\section{References}

1. Handisurya A, Moritz KB, Riedl E, Reinisch C, Stingl G, Wöhrl S. Fixed drug eruption caused by mefenamic acid: a case series and diagnostic algorithms. J Dtsch Dermatol Ges. 2011;9(5):374-8. doi: 10.1111/j.1610-0387.2011.07621.x.

2. Long CC, Finlay AY, Marks R. Fixed drug eruption to mefenamic acid: a report of three cases. Br J Dermatol. 1992;126(4):409-11.

3. Mahboob A, Haroon TS. Drugs causing fixed eruptions: a study of 450 cases. Int J Dermatol. 1998;37(11):833-8.

4. Muto M, Nichimura M, Kimura H. Fixed drug eruption due to mefenamic. Acta Dermatol-Kyoto. 1988;83:193-5.

5. Pérez-Pérez L, García-Gavín J, Allegue F, Zulaica A. Multifocal fixed drug eruption probably induced by mefenamic acid. Actas Dermosifiliogr. 2013;104(1):85-7. doi: 10.1016/j.ad.2012.02.012.

6. Rallis E, Rigopoulos D, Anyfantakis V, Kalogirou O, Christophidou E, Papadakis P, et al. 'Dalmatian dog'-like skin eruption (two cases of multifocal fixed drug eruption induced by mefenamic acid). J Eur Acad Dermatol Venereol. 2005;19(6):753-5.

7. Savin JA. Current causes of fixed drug eruption in the UK. Br J Dermatol 2001;145(4):667-8.

8. Bourns DCG. Unusual effects of antipyrine. Br Med J 1889;2:218-20.

9. Brocq L. Eruption érythémato-pigmentée fixe due a l'antipyrine. Ann Dermatol Venereol 1894;5:308-13.

10. Posadas SJ, Pichler WJ. Delayed drug hypersensitivity reactions - new concepts. Clin Exp Allergy 2007; 37(7):989-99.

11. Pellicano R, Ciavarella G, Lomuto M, Di Giorgio G. Genetic susceptibility to fixed drug eruption: evidence for a link with HLA-B22. J Am Acad Dermatol 1994;30(1): 52-4.

12. Ozkaya E. Fixed drug eruption: state of the art. J Dtsch Dermatol Ges. 2008;6(3):181-8.

13. Gruber F, Stasi'c A, Lenkovi'c M, Brajac I. Postcoital fixed drug eruption in a man sensitive to trimethoprim-sulphamethoxazole. Clin Exp Dermatol 1997;22(3):144-5.

14. Bilgili SG, Calka O, Karadag AS, Akdeniz N, Kosem M. Nonsteroidal anti-inflammatory drugs-induced generalized fixed drug eruption: two cases. Hum Exp Toxicol 2012;31(2):197-200. doi: 10.1177/0960327111412804.

15. Watson A, Watt G. Fixed drug eruption to mefenamic acid. Australas J Dermatol 1986;27(1):6-7. DOI: 10.1111/j.1440-0960.1986.tb00275.x.

16. Barbaud A, Gonçalo M, Bruynzeel D, Bircher A; European Society of Contact Dermatitis. Guidelines for performing skin tests with drugs in the investigation of cutaneous adverse drug reactions. Contact Dermatitis 2001; 45(6):321-8. 